\title{
Simulation tests of selected gas flow parameters through combustion engine valves
}

\begin{abstract}
The article presents the numerical analysis of a single-cylinder gasoline engine with indirect injection and spark ignition. The goal is to recognize and analyze gas flow through inlet and outlet valves and channels. These data were obtained from the simulation of a fourcycle engine cycle without combustion of the fuel-air mixture. The simulation was carried out in ANSYS, using a dedicated IC Engine module. After the simulation, the result was analyzed on the cross-sectional plane of both the valves and the combustion chamber. This method provided the necessary and concise representation of the flow characteristics. Five separate stages are presented - two describing the different displacement of the valve for each inlet and exhaust stroke and one representing the phenomenon of overlapping. The type of flow, its speed and tendency to create turbulence are described.
\end{abstract}

Key words: simulation, engines, Ansys, gas flow

\section{Introduction}

The road internal combustion engines have been defining the modern world for the last century. They are integral and essential part of the marine and overland spedition. While becoming more and more undesirable in environmentally conscious society, they still play overwhelmingly dominant role in today's private transportation. ICEs (Internal Combustion Engine) triumph is founded on the characteristics of petroleum fuels. Even in XXI century, petroleum distillates are the best widely available energy carriers. While ICEs are being burdened with a wide range of flaws, such as low efficiency, complex design, extensive maintenance required or noise, they are still the most reliable and feasible source of motion available. These features, along with the long history of automotive experiences, make the ICEs still the most popular option [1, 2].

At the end of the $20^{\text {th }}$ century, when the geopolitical situation was more or less stabilized, issues of global warming and climate change were revealed. It was pointed out that the means of transport have a significant impact on the emission of harmful compounds to the environment. With the introduction of Euro regulations aimed at reducing emissions of harmful compounds from vehicles, automotive manufacturers have received an ultimatum - either you are investing in technology that reduces these emissions, or your vehicles will not be allowed on the roads of the countries signing the agreements $[1,2,11,13]$.

There are two main methods for reducing engine exhaust emissions. The first, best prevention or reduction of their formation, i.e. the formation of processes in the cylinder, which include: design factors, fuel injection systems, suitable fuels. Second, reducing emissions by non-engine methods (aftertreatment), i.e. the use of a combination of catalytic reactors and particulate filters, such as TWC Three Way Catalyst [6, 20].

To reach satisfying and acceptable emission rates while maintaining high efficiency of combustion process, advanced simulation technics are being used. CFD analysis is inherent component of engine design process. Not only it enables engineers to analyze the flow of gases within the entire engine assembly, including intake/exhaust manifolds and ports, but also to have the direct insight into combustion chamber and behavior of gas throughout every stroke $[3,7,17]$.
With the use of analytical calculations and material science it is possible to design given components of an engine with a proper mechanical properties and safety factor. However, those methods cannot answer questions concerning the actual flows occurring inside the engine. Parameters describing cross sectional area of intake/exhaust ports can give scalar information about the volume efficiency of the canals, while omitting valuable information about the flow of the medium. This example can be translated to almost every gas/fluid operating part of the engine, starting with intake system, cooling system, exhaust system, with the emphasis on the exhaust manifold, where the timing of exhaust pulses is vital to the proper, unobstructed expulsion of the exhaust fumes.

The mechanism of provision of fresh air/fuel mixture to the cylinder, with the following expulsion of exhaust fumes throughout the 4-stroke cycle should also be considered from this perspective. It is obvious that while poppet valves are the main solution used in present ICEs to seal the chamber during specified periods of time, they are hardly the best one. Their shape accompanied by the specific motion of their operation has huge impact on the flow of the air/fuel mixture, seriously affecting the process of combustion chamber refilling and gas expulsion. This is the reason why CFD analysis of combustion chamber during full engine cycle is often used - it provides essential information about the characteristics of flow and the thermodynamic processes taking place, e.g. compression.

The goal of this thesis is the analysis of the engine cycle by the means of numerical simulation and further comparison of it with the previously designed engine parameters. With the help of virtual model of engine cycle, flow phenomena occurring during valve movement, including valve overlap, will be closely observed and researched. With the results in form of cross sectional diagrams of flow type and velocity, theoretical parameters of the engine will be investigated and compared to their simulation correspondents.

\section{Researched engine}

The simulation is conducted for single-piston port injection SI engine, realizing 4-stroke cycle. Two exhaust and two intake valves are regulated by double overhead camshaft system driven by a timing belt. Cooling of the cylinder is conducted directly through wet sleeve cylinder liner, 
with additional coolant channels in cylinder head. Outer liquid cooling system is responsible for heat transfer and maintaining stable operational temperature of the engine. Design of the analyzed engine in the Fig. 1.

Parameters of the tested engine are presented in Table 1.

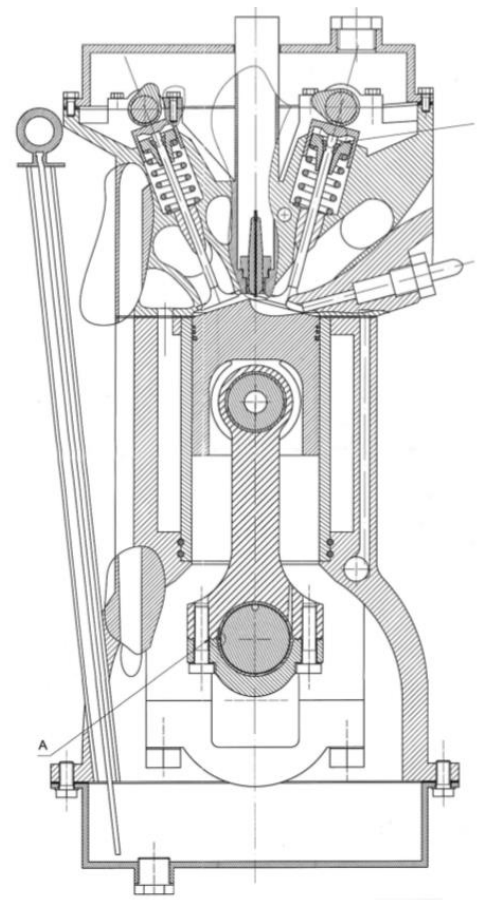

Fig. 1. Cross section of engine assemble [10]

Table 1. Design parameters of the engine [10]

\begin{tabular}{|c|c|c|}
\hline \multicolumn{3}{|c|}{ Mechanical parameters } \\
\hline Parameter & Value [unit] & Description \\
\hline 1 & $147 \mathrm{~mm}$ & Length of connecting rod \\
\hline $\mathrm{r}$ & $38.2 \mathrm{~mm}$ & Crank radius \\
\hline $\mathrm{D}$ & $85 \mathrm{~mm}$ & Cylinder bore \\
\hline $\mathrm{V}_{\mathrm{s}}$ & $432.5 \mathrm{~cm}^{3}$ & Engine displacement \\
\hline $\mathrm{S}$ & $76.4 \mathrm{~mm}$ & Piston stroke \\
\hline $\mathrm{H}_{\mathrm{i}}$ & $8.5 \mathrm{~mm}$ & Intake valve displacement \\
\hline $\mathrm{H}_{\mathrm{e}}$ & $7.5 \mathrm{~mm}$ & Exhaust valve displacement \\
\hline \multicolumn{3}{|c|}{ General parameters } \\
\hline \multicolumn{2}{|r|}{ Parameter } & Value \\
\hline \multicolumn{2}{|c|}{ Realized thermodynamic cycle } & $\begin{array}{c}\text { Otto cycle } \\
\text { (gasoline SI engine) }\end{array}$ \\
\hline \multicolumn{2}{|c|}{ Injection } & Port injection \\
\hline \multicolumn{2}{|c|}{ Cooling } & Liquid \\
\hline \multicolumn{2}{|c|}{ Valvetrain system } & DOHC \\
\hline \multicolumn{2}{|c|}{ Air/fuel ratio } & $14.4: 1$ \\
\hline Parameter & Value [unit] & Description \\
\hline $\mathrm{N}$ & $25 \mathrm{~kW}$ & Power \\
\hline $\mathrm{n}$ & $7000 \mathrm{rpm}$ & $\begin{array}{c}\text { Maximum revolutions } \\
\text { per minute }\end{array}$ \\
\hline $\mathrm{i}$ & 1 & Number of cylinders \\
\hline$\varepsilon$ & 9 & Compression ratio \\
\hline$\eta$ & $30.93 \%$ & Overall efficiency \\
\hline- & 4 & $\begin{array}{c}\text { Number of valves } \\
\text { per cylinder }\end{array}$ \\
\hline $\mathrm{P}_{\mathrm{i}}$ & $91 \mathrm{kPa}$ & Intake manifold pressure \\
\hline $\mathrm{P}_{\mathrm{e}}$ & $115 \mathrm{kPa}$ & Pressure in exhaust system \\
\hline $\mathrm{P}_{0}$ & $101 \mathrm{kPa}$ & Ambient pressure \\
\hline $\mathrm{T}_{0}$ & $300 \mathrm{~K}$ & Ambient temperature \\
\hline $\mathrm{g}_{\mathrm{e}}$ & $264.5 \mathrm{~g} / \mathrm{kWh}$ & Fuel consumption \\
\hline
\end{tabular}

\section{Simulation assumptions}

The due to complexity of simulation and limitations related to computing power of available computer, several assumptions and simplifications have to be introduced.

- Elimination of face radiuses - all inner surfaces of combustion chamber are modelled with sharp edges. Localized curvatures introduce high surface complexity, resulting in local mesh congestions. Increased number of mesh cells in these areas results in time-consuming calculations without much of an impact on the general analysis results. Model simplified in such a fashion, characterizes with satisfying credibility and optimal computation speed.

- Full air tightness - combustion chamber is fully sealed during compression and power stroke. It is assumed that piston ring seals are fully effective. With the blow-by loses ignored, there are no gas leakages piston throughout the cycle.

- Crevice volume omitted - crevice restricted by piston, cylinder and fire ring wall has no volume. While crevice does not have noticeable impact on the compression parameters, it introduces unwanted complications in the simulation model.

- Ambient temperature of the engine - all mechanical elements have negligible thermal conductivity and capacity. The temperature of the neighboring elements is stable and equal to ambient temperature throughout the cycle. No energy is introduced into the gas through the heat transfer from the boundary objects.

- Stable intake/exhaust pressure - no cyclic variations in intake/exhaust pressure are occurring throughout the cycle. In case of intake manifold, those can be effects of vacuum valve switching. In case of exhaust system, phenomenon of back pressure can severely restrict expulsion of gases.

- Ideal gas as a working medium - while simulating air/fuel mixture behavior, the ideal gas is used as a simulated medium. As the simulation does not cover the combustion, fuel addition in the air will only unnecessarily complicate simulation.

- No combustion - as the 4-stroke cycle is simulated with a use of a cold flow method, no combustion is taking place.

- Lengthened port channels - port channels are much longer to achieve equalized and even flow.

- Symmetry - due to the symmetry of the combustion chamber, only it's half will be calculated, to limit the necessary computing power.

- No spark plug - spark plug has been eliminated due to introduction of unnecessary complexity to the combustion chamber geometry.

Initially, dimensions are taken from the technical documentation [10] and each essential component of combustion chamber is modelled. Some undimensioned parts of complex shape, as intake/exhaust ports, are modelled with a personal input. With emphasis on the inner surfaces of combustion chamber, outer boundaries are omitted as they are not needed in the simulation. The model of the combustion chamber assembly is shown in Fig. 2. 
To conduct the cold flow simulation, inner volume of combustion chamber and intake/exhaust ports is required (Fig. 3). This volume is restricted by: piston face, cylinder lining, cylinder head niche, seating faces of four poppet valves and the intake/exhaust porting.

The piston must be positioned in TDC (Top Dead Center), and the valves must be positioned in the closed position. Additionally, bodies of the intake and exhaust valves should be included into the file with the combustion chamber volume extract. Due to the ANSYS requirements, valve seating face has to be moved from the cylinder head seating face by a small margin, in this case $0.1 \mathrm{~mm}$. This eliminates discontinuity in the flow phase by spreading apart boundaries of valve body and the cylinder head seating face $[15,18]$.

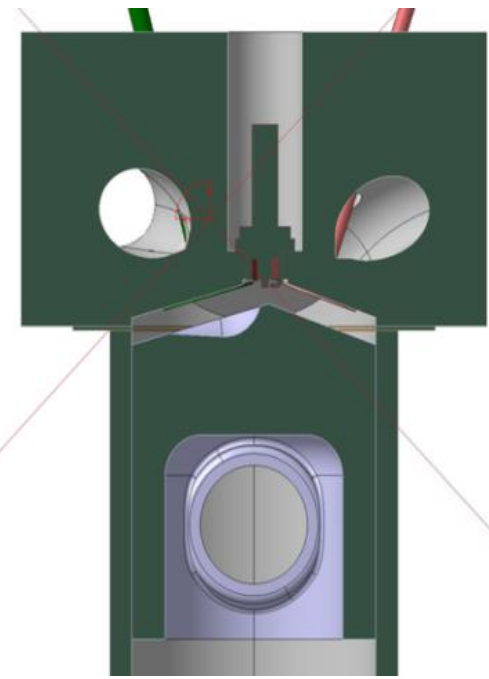

Fig. 2. Model of combustion chamber assembly

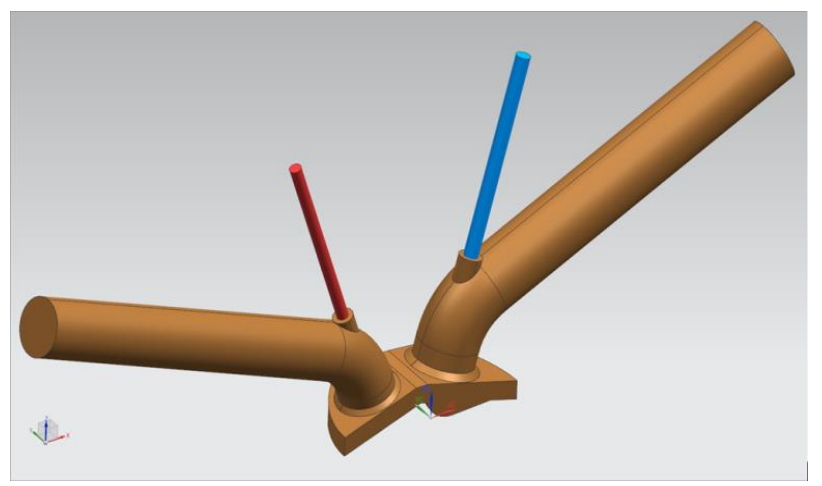

Fig. 3. Model of combustion chamber assembly

\section{Design methodology}

\subsection{Style for figures}

The simulation will be conducted in the ANSYS Products software, using IC Engine module. As the flow of the gas is directly dependent from crankshaft angle (phase of the engine cycle), transient simulation must be conducted. Due to variable volume of the combustion chamber and cyclic motion of the valves, dynamic mesh must be introduced. IC Engine module has integrated tools for automatic dynamic mesh construction, although they are unreliable and require extensive manual calibration. The model preparation consists of 5 main steps:
1. Model decomposition

2. Mesh parametrization

3. Mesh generation

4. Application of boundary conditions

5. Simulation process

Input model is split into array of characteristic sections required by the program. These parts carry individual information about the type of it's mesh and the meshing order (Table 2).

Table 2. In-program nomenclature of the decomposed bodies [9]

\begin{tabular}{|c|l|c|}
\hline No. & \multicolumn{1}{|c|}{ Fluid Zone Name } & Mesh requirement \\
\hline 1 & fluid - ch & any mesh \\
\hline 2 & fluid - valveID - ib & $\begin{array}{c}\text { mesh with at least one layer at the } \\
\text { top }\end{array}$ \\
\hline 3 & fluid - valveID - port & any mesh \\
\hline 4 & fluid - valveID - vlayer & layered mesh \\
\hline 5 & fluid - crevice & any mesh \\
\hline
\end{tabular}

Section 1 recreates closed combustion chamber. Section 2 involves volume directly adhered to the valve stem. Section 3 recreates the intake/exhaust port volume. Section 4 recreates the seal created by valve being fully closed. Section 5 recreates crevice existing between piston cylindrical face, cylinder lining and fire ring (Figs. 4, 5).

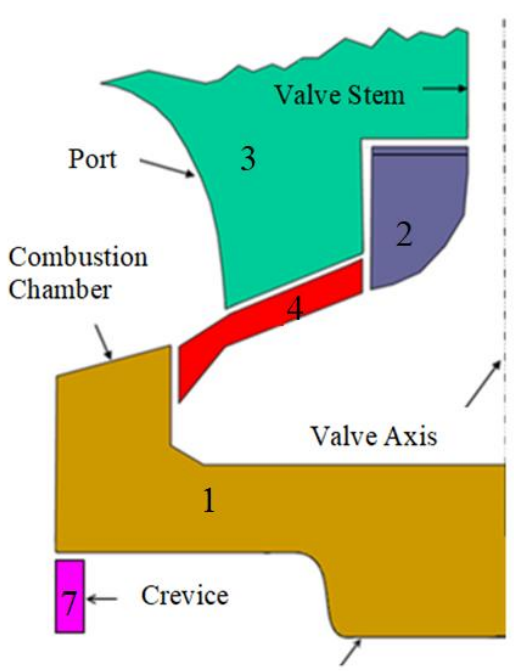

Piston Bowl

Fig. 4. Separate sections created in decomposition process [9]

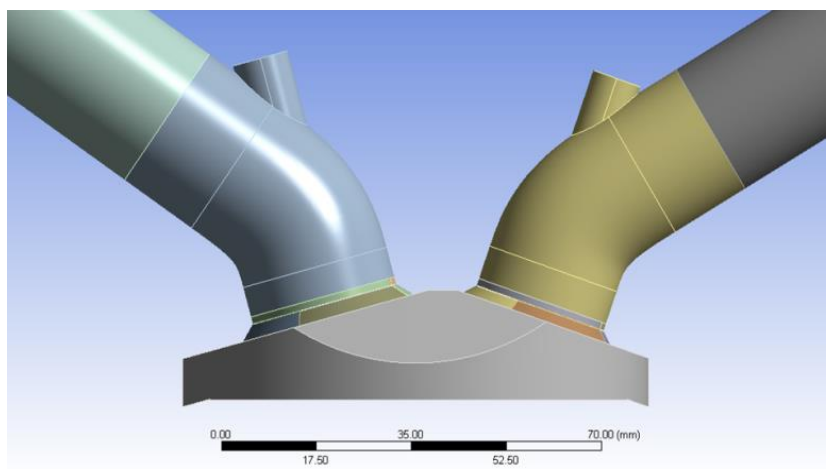

Fig. 5. Separate sections created in decomposition process [9] 
First step of the meshing process is mesh parametrization. While whole sequence is automatic, user has possibility to configure mesh parameters of every decomposed body in terms of sizing, inflation and spacing. During mesh generation, ANSYS meshes decomposed body in set order, following previously mentioned parameters [5, 8, 12]. Mesh of whole geometry is shown in figure 6 and cross section of the valve mesh in Fig. 7.

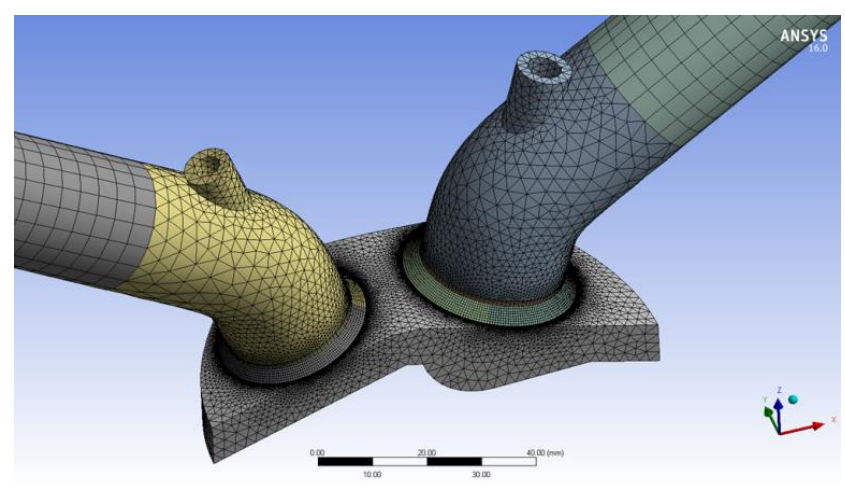

Fig. 6. Mesh of whole geometry

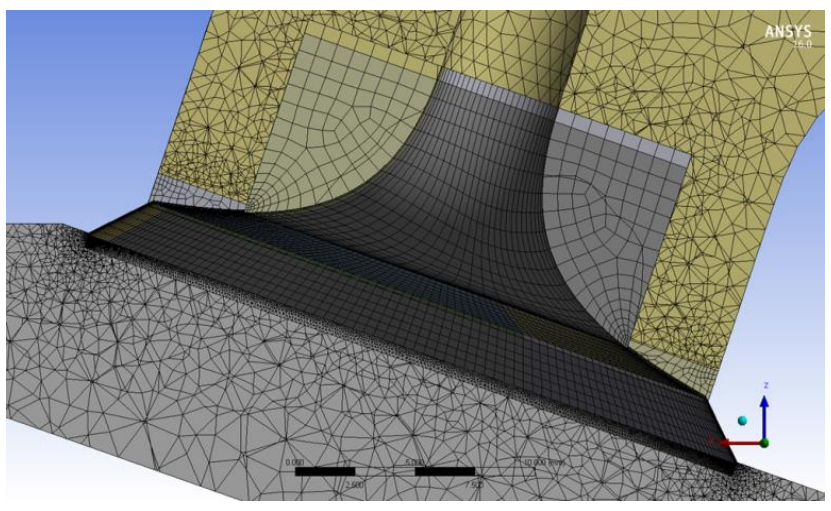

Fig. 7. Cross section of the valve mesh

Unfortunately, automatically generated mesh features a huge amount of mesh defects, yielding very poor mesh quality, essential for a successful simulation. Further mesh refinement of sections adjacent to valves, deletion of port inflation and modification of meshing methods results in mesh of satisfying quality. While minimal orthogonal quality assumes good number of 0.19 , maximal cell skewness equals to 0.9 , which is borderline satisfactory result for computable mesh. The improved mesh is shown in the Fig. 8.

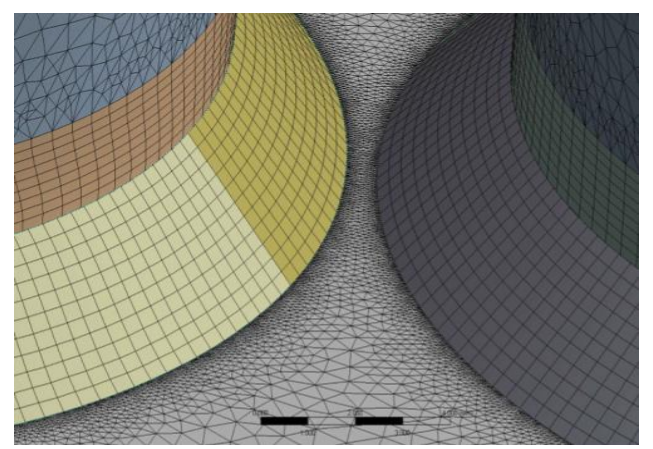

Fig. 8. High refinement of combustion chamber mesh cells adjacent to valve seals

\subsection{Boundary conditions}

For the simulation to run properly, a group of initial conditions must be set [14]. Those conditions not only regulate the cycle of the engine, but also directly influence the flow and behavior of the air/fuel mixture. Technical data of the researched engine provides information about values of these conditions. Following boundary conditions are being set:

- Intake pressure - value of underpressure created in the intake manifold due to continuous suction of fresh air into the combustion chamber. In the discussed engine, the intake pressure is $10 \mathrm{kPa}$ lower than ambient pressure, equaling $91 \mathrm{kPa}$, that mean the engine full load work condition (Throttle Wide Open).

- Exhaust pressure value of elevated pressure existing in the exhaust manifold due to continuous expulsion of exhaust gases to the restricted system. In the discussed engine, the exhaust pressure is $14 \mathrm{kPa}$ higher than ambient pressure, equaling $115 \mathrm{kPa}$.

- Revolutions per minute - simulated cycle is taking place at $1800 \mathrm{rpm}$.

- Combustion chamber temperature - as previously assumed, all combustion chamber boundaries have ambient temperature of $300 \mathrm{~K}$.

The k-omega SST model was chosen for flow simulation, since k-epsilon is not able to capture the appropriate turbulent behavior of the boundary layer until it is detached [5]. The SST turbulence model $\mathrm{k}-\omega$ is a two-equation model hybrid. It is a smooth transition from the k-omega standard model, used in the boundary layer, for the model $\mathrm{k}-\varepsilon$ as far as moving away from the surface that limits flow. Contains modified formulation of turbulent viscosity for the purpose taking into account the effect of transport of main shear stresses.

\section{Result analysis}

\subsection{Analysis methodology}

For the simulation the simulated data will be presented in form of charts placed on the plane sectioning both valves. This method will provide essential and concise depiction of flow characteristics. Five separate stage samples will be presented - two describing different valve displacement for each intake and exhaust stroke and one depicting overlap phenomenon.

Each stage sample will be analyzed with regard to two best suited parameters describing flow of the gas - it's magnitude velocity, portrayed by contour charts and turbulence kinetic energy (TKE) which will be presented as contour charts as well.

The TKE is defined to be half the sum of the variances of the velocity components and can be description [24]:

$$
\mathrm{TKE}=\frac{1}{2}\left(\overline{\left(\mathrm{u}^{\prime}\right)^{2}}+\overline{\left(\mathrm{v}^{\prime}\right)^{2}}+\overline{\left(\mathrm{w}^{\prime}\right)^{2}}\right)
$$

where the turbulent velocity component is the difference between the instantaneous and the average velocity $\mathrm{u}^{\prime}=\mathrm{u}-\overline{\mathrm{u}}$, whose mean and variance are:

$$
\overline{\mathrm{u}^{\prime}}=\frac{1}{\mathrm{~T}} \int_{0}^{\mathrm{T}}(\mathrm{u}(\mathrm{t})-\overline{\mathrm{u}}) \mathrm{dt}=0 \text { and }
$$




$$
\overline{\left(\mathrm{u}^{\prime}\right)^{2}}=\frac{1}{\mathrm{~T}} \int_{0}^{\mathrm{T}}(\mathrm{u}(\mathrm{t})-\overline{\mathrm{u}})^{2} \mathrm{dt} \geq 0 .
$$

This will give us precise information about the type and dynamic parameters of the flow taking place in every spot of the combustion chamber and intake/exhaust porting.

\subsection{Exhaust stroke with $3.75 \mathrm{~mm}$ exhaust valve displacement}

With the valve opened halfway through, the flow characteristic becomes discernible. Gases are being expulsed through the crevice created between valve and the seating face of the cylinder head, and pushed onto the valve stem. They are forced around the valve stem, then proceed along the upper wall of the exhaust channel and the valve guide. As the gas velocity in the reducer reaches speed of about $200 \mathrm{~m} / \mathrm{s}$, it carries significant portion of kinetic energy. There are few significant technological flaws in the exhaust porting itself. Firstly, due to incorrect curvature of the exhaust channel wall, localized, highly turbulent flow occurs in the upper section of the channel, directly next the valve stem. This results in high local flow resistance, negatively impacting engine's capability to expulse exhaust gases. Parameters were tested during the simulation of velocity (Fig. 9) and turbulence (Fig. 10) [15].

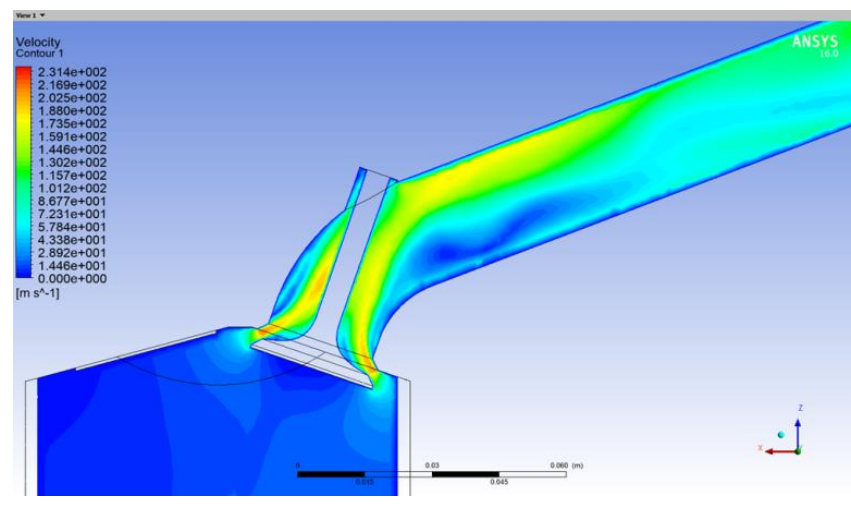

Fig. 9. Contour chart of the velocity of flow during exhaust stroke with $3.75 \mathrm{~mm}$ exhaust valve displacement

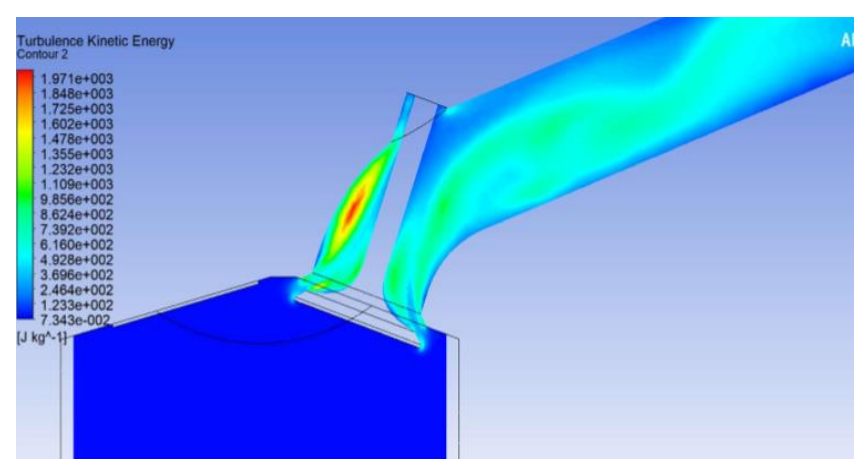

Fig. 10. Contour chart of the turbulence kinetic energy of flow during exhaust stroke with $3.75 \mathrm{~mm}$ exhaust valve displacement

\subsection{Exhaust stroke with $7.5 \mathrm{~mm}$ exhaust valve displacement}

As the exhaust valve reaches maximal displacement, highest volumetric flow is achieved. The maximal velocity of gases is further increased, reaching about $240 \mathrm{~m} / \mathrm{s}$ in the reducer, and spans on much higher volume. Therefore, flow issues become more dominant, resulting in three localized turbulence zones. Parameters were tested during the simulation of velocity (Fig. 11) and turbulence (Fig. 12). First one possesses same characteristics as in previous stage sample. Second one, is a direct effect of exhaust gasses hitting the valve stem at high speed, and is a design flaw of this particular combustion chamber sealing solution.

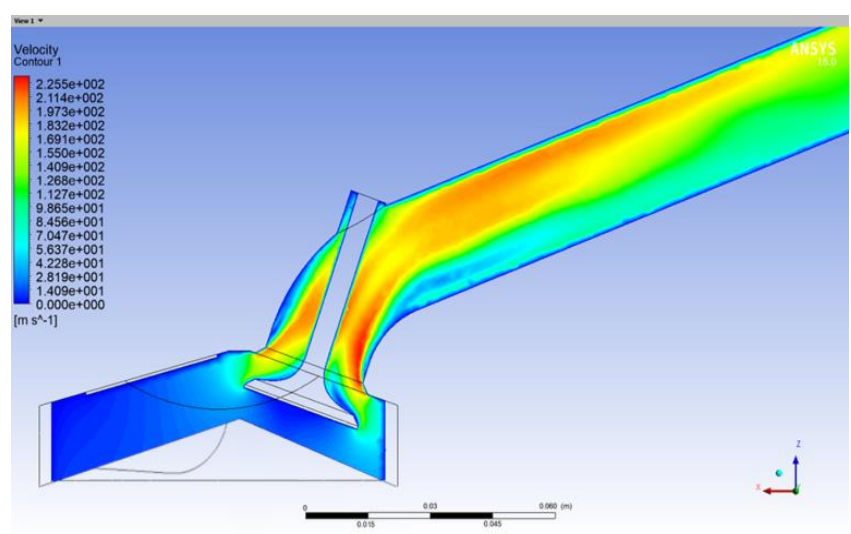

Fig. 11. Contour chart of the velocity of flow during exhaust stroke with $7.5 \mathrm{~mm}$ exhaust valve displacement

Third turbulence zone is located next to the lower wall of the exhaust channel, and is a result of gasses being peeled off the main flow streamline, and having tendency to eddy against the main flow. The valve guide cutout also poses a significant problem, as it breaks the smoothness of the channel wall, resulting in gasses being trapped inside it and inducing further turbulences [15].

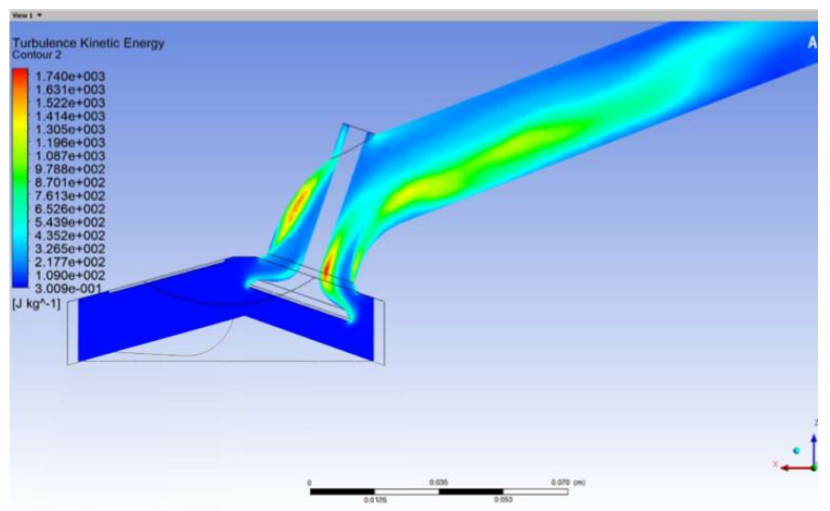

Fig. 12. Contour chart of the turbulence kinetic energy of flow during exhaust stroke with $7.5 \mathrm{~mm}$ exhaust valve displacement

\subsection{Overlap phase with $2 \mathrm{~mm}$ exhaust and intake valve displacement}

On most engines, during a short angle span of the crankshaft rotation, both valves are simultaneously opened with a certain displacement. In theory, this allows for inflow of fresh air/fuel mixture into the combustion chamber, and further ventilation of the post-combustion gases. This process generally increases the cleanliness and efficiency of the combustion itself. Simulation has shown that while the actual ventilation does take please, resulting in a flow of the gases from intake to the exhaust channel, this flow seems almost completely separated from the combustion chamber volume. Parameters were tested during the simulation of velocity (Fig. 13) and turbulence (Fig. 14). 
Assumption was made, that the coldflow type of the simulation affect this process. Lack of the post-combustion gases results in different, unrealistic pressure in the combustion chamber, introducing the deviations in the simulation model. It is important to note, that while combustion chamber is not involved in the gas exchange, the flow from the intake valve actually moves the masses of gas which are located in the corner of the cylinder head. These masses were virtually trapped in that corner during both stage samples of exhaust stroke (it's velocities were close to 0 ), resulting in poor ventilation of these areas.

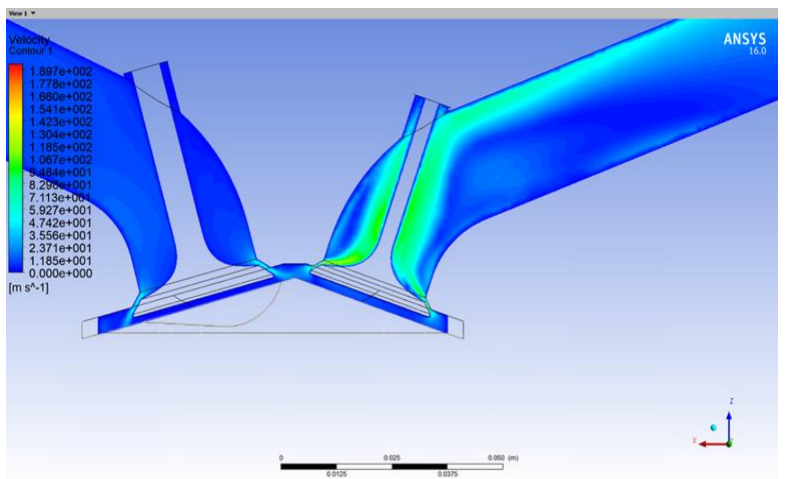

Fig. 13. Contour chart of the velocity of flow during overlap phase with $2 \mathrm{~mm}$ exhaust and intake valve displacement

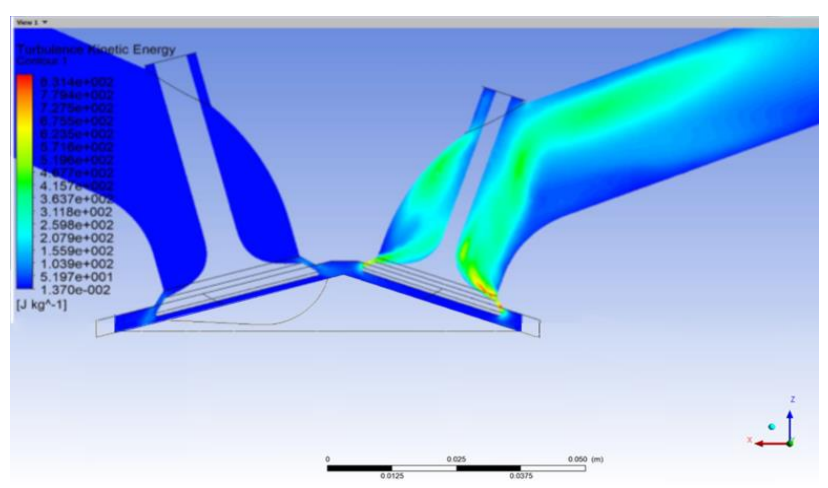

Fig. 14. Contour chart of the turbulence kinetic energy of flow during overlap phase with $2 \mathrm{~mm}$ exhaust and intake valve displacement

It means that the overlap, while not providing noticeable impact on the gas exchange, does improve gas circulation in the combustion chamber. Another theory implies that design of the combustion chamber is flawed, with the valves being too close to each other [15].

\subsection{Intake stroke with $4.25 \mathrm{~mm}$ intake valve displacement}

During the intake stroke, intake valve is opened for a fresh air/fuel mixture to enter the combustion chamber. The shape and curvature of streamlines formed by the gas entering the combustion chamber is extremely important proper mixing of the gas inside the chamber will positively impact the combustion process, eliminating hot spots, lowering the emission of toxic fumes and limiting knocking. The flow of the gas is much more ordered, compared to the exhaust stroke. Throughout the intake channel, turbulence kinetic energy of the gas is very low, and the flow can be described as laminar. This is not surprising, as the shape of crevice and intake channel directs the air flow in much more orderly fashion. Due to that fact, velocities of the gas reach the maximal value of $60 \mathrm{~m} / \mathrm{s}$, but typically are oscillating around $40 \mathrm{~m} / \mathrm{s}$. It is worth noticing how the flow is directed by the cylinder walls, and further by the piston. This leads to the formation of swirls inside the combustion chamber, resulting in throughout mixing. Parameters were tested during the simulation of velocity (Fig. 15) and turbulence (Fig. 16).

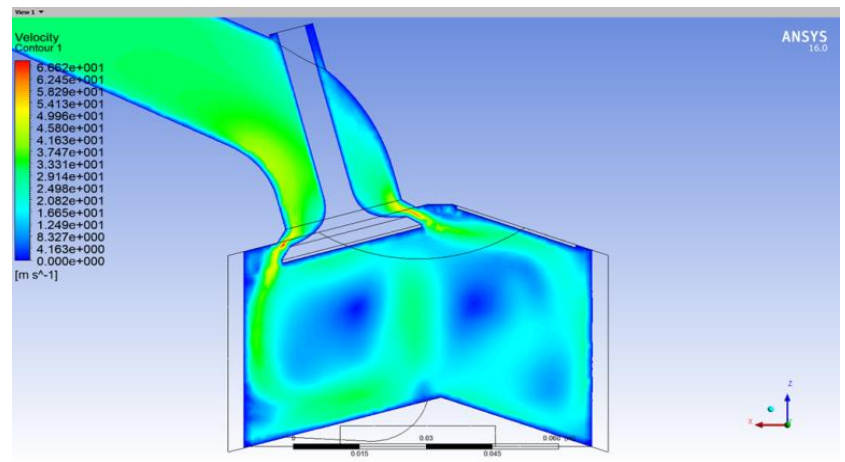

Fig. 15. Contour chart of the velocity of flow during intake stroke with $4.25 \mathrm{~mm}$ intake valve displacement

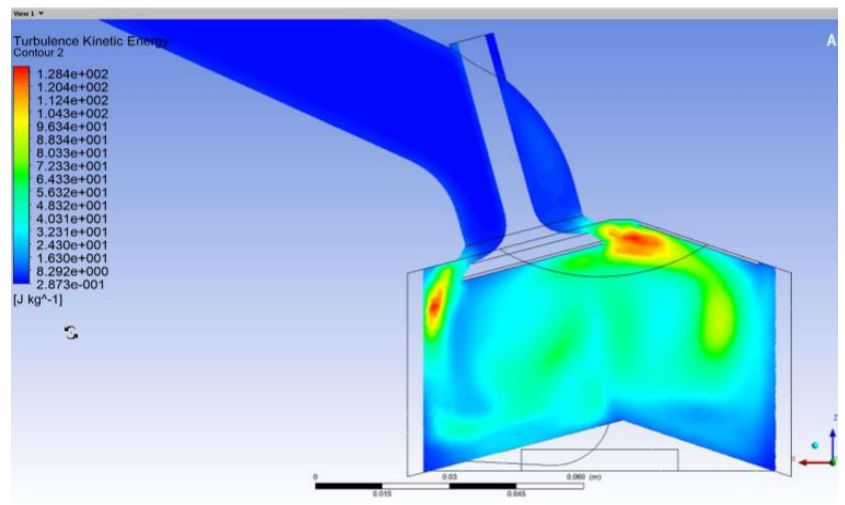

Fig. 16. Contour chart of the turbulence kinetic energy of flow during intake stroke with $4.25 \mathrm{~mm}$ intake valve displacement

Two noticeable turbulence zones occur - both are positioned in the combustion chamber, in closed proximity to the intake valve. They are created by the inflowing gas bouncing of the edge of the valve's seating face [15].

\subsection{Intake stroke with $8.5 \mathrm{~mm}$ intake valve displacement}

With the intake valve fully open, the maximal volumetric flow occurs. All described phenomena in the previous stage sample are gaining on intensity. Parameters were tested during the simulation of velocity (Fig. 17) and turbulence (Fig. 18).

Mixing of the gas inside the combustion chamber is much more erratic, with the swirls noticeable, but much less visible than in previous stage sample. The velocity of the gas does not change, and ranges from the maximum of $60 \mathrm{~m} / \mathrm{s}$, to the average of $40 \mathrm{~m} / \mathrm{s}$. It should be pointed out that the turbulences occurring in close proximity to valve, during early stages of intake valve opening, are decreasing, and even disappearing with the increase of intake valve displacement [15]. 


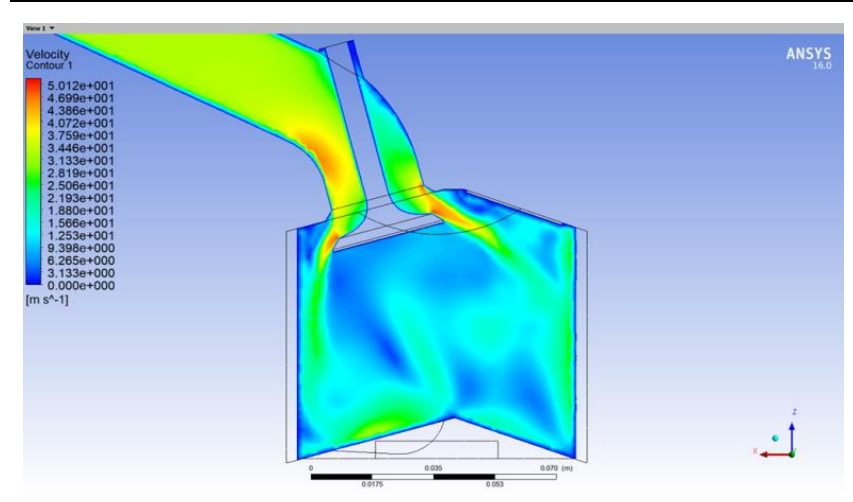

Fig. 17. Contour chart of the velocity of flow during intake stroke with $4.25 \mathrm{~mm}$ intake valve displacement

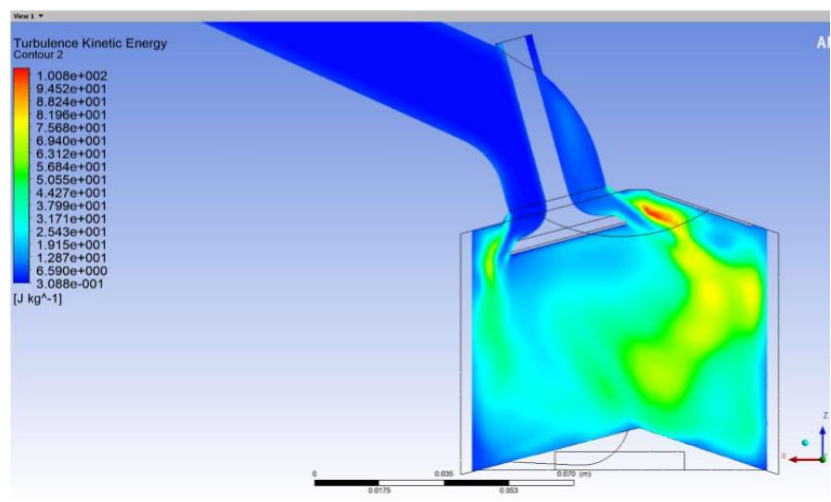

Fig. 18. Contour chart of the turbulence kinetic energy of flow during intake stroke with $8.5 \mathrm{~mm}$ intake valve displacement

\section{Thermodynamic analysis}

Due to high complexity of flow occurring throughout the combustion chamber volume, thermodynamic parameters are ought to change. As the pressure and temperature are strictly bound to the type of flow and it's velocity, it already can be concluded that evident pressure and temperature gradient will arise. While simulation model does not include temperature convection, it does feature ideal, compressible gas, meaning the temperature of the gas will fluctuate depending from the pressure and flow it experiences. All pressure values are relative to the ambient pressure, which means, that absolute pressure value is sum of gauge pressure and ambient pressure.

- Exhaust stroke with $3.75 \mathrm{~mm}$ exhaust valve displacement. The exhaust stroke is happening with stable pressure of $77 \mathrm{kPa}$ inside the combustion chamber. As the flow of the gas is accelerated inside the exhaust channel, it's pressure drops to average of $20 \mathrm{kPa}$. Local discontinuities in exhaust channel surface, like valve guide cutout restrict the flow, locally increasing the pressure up to $25 \mathrm{kPa}$. Temperature of the gas in the main streamlines is significantly lower compared to the surroundings, and ranges from 250 to $275 \mathrm{~K}$. As the highest flow is achieved in the valve crevice, it is also the point of highest decompression and lowest temperature.

- Exhaust stroke with $7.5 \mathrm{~mm}$ exhaust valve displacement. The value of exhaust stroke pressure inside the combustion chamber changes slightly to $76 \mathrm{kPa}$. The flow is significantly stronger, leading to the further drops of pressure and temperature. In the main stream- lines temperature drops down to $250 \mathrm{~K}$ while the absolute pressure value oscillates around the ambient pressure value. Pressure inside the exhaust channel averages around $6 \mathrm{kPa}$.

- Intake stroke with $4.25 \mathrm{~mm}$ intake valve displacement. In the early stage of intake valve opening, the flow is low and ordered enough to not cause high temperature and pressure changes. With the exception of valve crevice where temperature drops about $6 \mathrm{~K}$, it is uniform across the volume of the combustion chamber and oscillates around $300 \mathrm{~K}$.

- Intake stroke with $8.5 \mathrm{~mm}$ intake valve displacement. With the valve fully extended, intake flow is much higher. This results in small temperature gradient forming in the combustion chamber, with the maximum gradient (of about $2 \mathrm{~K}$ ) located similarly to previous stage samples, in the valve crevice.

\section{Conclusions}

In CFD methods, the problem is the interpretation of results, because the computer "counts everything", unfortunately not always in accordance with the physical characteristics of the phenomenon. This requires a skillful interpretation of the results $[4,16,23]$.

While this engine project in theory fulfilled every design criterion, analytical calculations never actually included the gas exchange occurring inside the intake/exhaust ports and combustion chamber. CFD analysis proved useful in defining parameters of simulated flow, and it's visualization inside the combustion chamber. It also pointed out several design features that can be altered in order to achieve smoother, less disturbed and what's more, less resistive flow. Following features seem to negatively impact the flow of the gas:

- Exhaust channel curvature - wrong curvature induces reverse flow in the proximity of valve stem (Figs 9, 11). Introduction of lower curvature channel would unify the flow around the stem, but what's more important, it would minimalize the turbulence.

- Exhaust channel cross sectional area - an alteration of exhaust channel cross section into the oval instead of circle seems to unify the flow throughout the whole width of the exhaust channel, eliminating elongated turbulence zone (Figs 9, 11).

- Intake and exhaust valve position in combustion chamber - as the gas exchange during the valve overlap seems poor, increased distance between intake and exhaust valve would theoretically force the inert combustion chamber gases to participation in this exchange.

- Exhaust valve guide cutout - as the valve guide cutout poses a significant flow obstacle, decreases in this size or shape would bring positive effect on. When the mechanical construction of poppet valve does not allow us to do so, cast radiuses are the alternative.

As the simulated values of flow's velocity differ significantly from the theoretical values, it is important to analyze the factors that could somehow affect the flow to such extent. In theoretical calculations, this values are selected based on statistic data regarding flow in intake/exhaust port of the industrial engines [22]. That data is extremely impre- 
cise, and provides only an estimation of the real-life values. The CFD analysis takes into account not only the cross sectional area of the intake/exhaust channels, but also examines their curvature and every obstruction which can lead to separation and turbulences of the flow. Those obstacles might be of any kind, like the valve stem, valve guide cut out, seating face of the cylinder head and so on. Therefore, while theoretical calculations are based on the extract data from statistics, real-life parameters might have completely different value.
In the CFD calculation methods, the interpretation of results is an important aspect. These methods give results that in many cases are demonstrative and not always consistent with the physical characteristics of the phenomenon. They can be used as preliminary tests for real-world tests, initial selection of structural parameters and designing changes. By extending knowledge in the field of frequency analysis of pulsation of pressure with the influence of work, design and thermodynamic parameters on the spectrum of the signal, a tool can be created for effective and quick assessment of changes in the system [19, 21].

\section{Nomenclature}

CFD computational fluid dynamics

DOHC double overhead camshaft

ICE internal combustion engine $\begin{array}{ll}\text { SI } & \text { spark ignition } \\ \text { TDC } & \text { Top Dead Center }\end{array}$

\section{Bibliography}

[1] KALGHATGI, G.T. Developments in internal combustion engines and implications for combustion science and future transport fuels. Proceedings of the Combustion Institute. 2015, 35(1), 101-115.

https://doi.org/10.1016/j.proci.2014.10.002

[2] NABER, J.D., JOHNSON, J.E. Alternative fuels and advanced vehicle technologies for improved environmental performance. Woodhead Publishing. 2014, 197-224.

https://doi.org/10.1533/9780857097422.1.197

[3] HONG, H., PARVATE-PATIL, G.B., GORDON, B. Review and analysis of variable valve timing strategies - eight ways to approach. Proceedings of the Institution of Mechanical Engineers, Part D: Journal of Automobile Engineering. 2004, 218(10), 1179-1200.

https://doi.org/10.1177/095440700421801013

[4] GÓRNIAK, A., MICHAŁOWSKI, R., TKACZYK, M. Symulacje układu dolotowego silnika zasilanego CNG. $\mathrm{Au}$ tobusy. 2011, 12.

[5] ANSYS Meshing User's Guide_r130.pdf. ANSYS 2013.

[6] MERKISZ, J., PIELECHA, J., RADZIMIRSKI, S. Emisja zanieczyszczeń motoryzacyjnych. Wydawnictwa Komunikacji i Łaczności. Warszawa 2012.

[7] WILCOX, D. Turbulence modeling for CFD. KNI, Inc., Anaheim, 2002.

[8] THOMPSON, J., WARSI, Z., MASTIN, C. Numerical grid generation. Foundations and applications. Elsevier Science Publishing Co., Inc., New York 1985.

[9] SHARCNET

https://www.sharcnet.ca/Software/Ansys/17.0/enus/help/wb _icom_decomp_part_bods_pis3 .html [Accessed 15.5.2019]

[10] CIEŚLIK, W. Silnik spalinowy ZI. Projekt. Politechnika Poznańska. Poznań 2011.

[11] WAJAND, J.A., WAJAND, J.T. Tłokowe silniki spalinowe średnio- i szybkoobrotowe. Wydawnictwa Naukowo-Techniczne. Warszawa 2003.

[12] ANSYS-Fluent-Tutorial-Guide_r170.pdf

[13] http://zss.lublin.eu/wp-content/uploads/2016/09/2.5-Processpalania.pdf, 12.01.2019.
[14] FORTUNA, Z., MACUKOW, B., WĄSOWSKI, J. Metody numeryczne. Wydawnictwa Naukowo-Techniczne. Warszawa 1982.

[15] KAWECKI, J. Evaluation of selected thermodynamic parameters in simulation tests of an internal combustion engine. Master's thesis. Wroclaw 2019.

[16] TUTAK, A., JAMROZIK, A. Modelling of the thermal cycle of a gas engine using AVL FIRE Software. Combustion Engines. 2010, 141(2).

[17] TUTAK, W. Modelowanie i analiza wybranych parametrów obiegu cieplnego silnika tłokowego z EGR. Combustion Engines. 2011, 147(4).

[18] HEYWOOD, J.B. Internal combustion engines fundamentals. McGraw-Hill, New York 1988.

[19] TUTAK, W. Interpretacja wyników pomiarów prędkości przepływu ładunku w komorze spalania tłokowego silnika spalinowego. Pomiary Automatyka Kontrola. 2008, 54(2).

[20] ANDRYCH-ZALEWSKA, M., CHŁOPEK, Z., MERKISZ, J. et al. Evaluation of the test drive cycle conditions impact on exhaust emissions from an internal combustion engine. Combustion Engines. 2018, 175(4), 3-9. https://doi.org/10.19206/CE-2018-401

[21] PYSZCZEK, R., SCHMALHORST, C., TEODORCZYK, A. Numerical investigation on diesel combustion and emissions with a standard combustion model and detailed chemistry. Combustion Engines. 2015, 162(3), 19-33.

[22] GĘCA, M., HUNICZ, J., JAWORSKI, P. Numerical investigation into the effect of direct fuel injection on thermal stratification in HCCI engine. Combustion Engines. 2017, 169(2), 137-140. https://doi.org/10.19206/CE-2017-224

[23] KOWALSKI, J. The CFD analysis of influence the start of fuel injection (SOI) on combustion parameters and exhaust gas composition of the marine 4-stroke engine. Combustion Engines. 2019, 177(2), 40-45. https://doi.org/10.19206/CE2019-207

[24] POPE, S.B. Turbulent flows. Cambridge University Press. 2000, 122-134. 